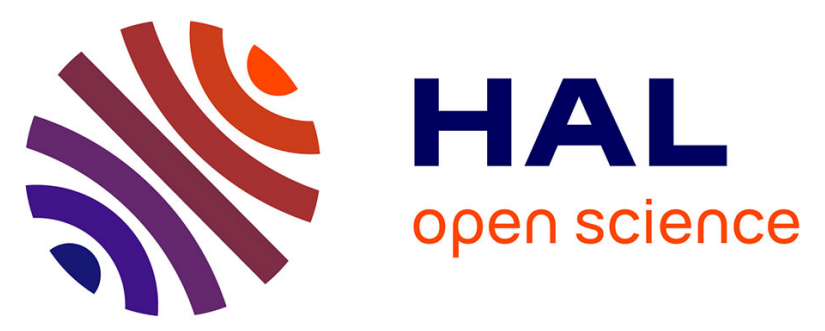

\title{
Adsorption of lactate dehydrogenase enzyme on carbon nanotubes: how to get accurate results about the cytotoxicity of these nanomaterials
}

Valérie Forest, Agathe Figarol, Delphine Boudard, Michèle Cottier, Philippe Grosseau, Jérémie Pourchez

\section{To cite this version:}

Valérie Forest, Agathe Figarol, Delphine Boudard, Michèle Cottier, Philippe Grosseau, et al.. Adsorption of lactate dehydrogenase enzyme on carbon nanotubes: how to get accurate results about the cytotoxicity of these nanomaterials. Langmuir, 2015, 31 (12), pp.3635-3643. 10.1021/acs.langmuir.5b00631 . hal-01133372

\section{HAL Id: hal-01133372 https://hal.science/hal-01133372}

Submitted on 24 Apr 2015

HAL is a multi-disciplinary open access archive for the deposit and dissemination of scientific research documents, whether they are published or not. The documents may come from teaching and research institutions in France or abroad, or from public or private research centers.
L'archive ouverte pluridisciplinaire HAL, est destinée au dépôt et à la diffusion de documents scientifiques de niveau recherche, publiés ou non, émanant des établissements d'enseignement et de recherche français ou étrangers, des laboratoires publics ou privés. 
Adsorption of lactate dehydrogenase enzyme on carbon nanotubes: how to get accurate results about the cytotoxicity of these nanomaterials

Valérie Forest* 1,2,3, Agathe Figarol2,3,4, Delphine Boudard2,3,5,6,7, Michèle Cottier²,3,5,6,7, Philippe Grosseau ${ }^{4}$, Jérémie Pourchez ${ }^{1,2,3}$.

1 Ecole Nationale Supérieure des Mines de Saint-Etienne, CIS, Saint-Etienne, France.

2 LINA, EA4624, Saint-Etienne, France.

3 SFR IFRESIS, Saint-Etienne, France.

4 Ecole Nationale Supérieure des Mines de Saint-Etienne, SPIN, CNRS: UMR 5307, LGF, Saint-Etienne, France.

5 Faculté de Médecine J. Lisfranc, Université Jean Monnet Saint-Etienne, France.

6 PRES Lyon, France.

7 CHU Saint-Etienne, France.

* Corresponding author: Valérie Forest: vforest@emse.fr 


\section{Abstract:}

Carbon nanotubes (CNT) cytotoxicity is frequently investigated using in vitro classical toxicology assays. However these cellular tests, usually based on the use of colorimetric or fluorimetric dyes, were designed for chemicals and may not be suitable to nano-sized materials. Indeed, due to their unique physico-chemical properties CNT can interfere with the assays and bias the results. To get accurate data and draw reliable conclusions, these artifacts should be carefully taken into account. The aim of this study was to evaluate qualitatively and quantitatively the interferences occurring between $\mathrm{CNT}$ and the commonly used lactate dehydrogenase (LDH) assay. Experiments in cell free conditions were performed and it was clearly demonstrated that artifacts occurred. They were due to the intrinsic absorbance of CNT on one hand and to the adsorption of LDH at the CNT surface on the other hand. The adsorption of LDH on CNT was modeled and was found to fit the Langmuir model. The $\mathrm{K}_{\mathrm{ads}}$ and $\mathrm{n}_{\mathrm{eq}}$ constants were defined, allowing the correction of results obtained from cellular experiments to get more accurate data and lead to proper conclusions on the cytotoxicity of CNT.

\section{Key-words:}

Carbon nanotubes, cytotoxicity, LDH assay, nanomaterial/assay interferences. 


\section{Introduction:}

The use of nanomaterials in general and of carbon nanotubes $(\mathrm{CNT})$ in particular has incredibly increased during the last decades. Due to their exceptional physico-chemical properties CNT exhibit promising applications, in fields as varied as material sciences, microelectronics and even medicine ${ }^{1,2} \ldots$ This extensive use results in an increased risk of exposure for workers and consumers therefore leading to a growing need for accurate cytotoxicity assays. For that purpose in vitro cellular assays are usually used. Although insufficient to draw firm conclusions they are useful for a rapid screening of the cellular response in terms of cytotoxicity, pro-inflammatory effect, oxidative stress, genotoxicity... but only if they are conducted properly. Indeed, in nanotoxicological studies, standard toxicological assays are used but these latter were developed for chemicals and they may not be suitable for these particular nanomaterials ${ }^{3-5}$. These assays use colorimetric or fluorimetric dyes as markers to determine cell viability assessing membrane integrity or cell metabolism. Due to their high surface area, nanomaterials can interfere with the assay components or products and bias the results, potentially leading to misinterpretations. Besides, this has been proposed as a partial explanation for the conflicting results reported in the literature about the cytotoxicity of nanomaterials ${ }^{6}$ and especially CNT.

For example, Wörle-Knirsch et al..$^{7}$ have demonstrated that CNT could trigger false-positive results with one of the most popular cytotoxicity assay: the MTT test. This assay is based on the conversion of a yellow tetrazolium salt: the MTT [3-(4,5-Dimethyl-2-thiazolyl)-2,5diphenyl-2H-tetrazolium bromide] into an insoluble purple formazan precipitate. This reduction is carried out by the mitochondria of viable cells and therefore the amount of formazan formed (quantified by measuring the absorbance at $570 \mathrm{~nm}$ ) is directly proportional to cell viability. CNT have been shown to interact with the tetrazolium salts used in this test (but not with that used in variants of this assays such as the WST-1, INT or XTT assays $)^{7}$ making impossible the MTT conversion into formazan. This interference was 
confirmed by Belyanskaya et al..$^{8}$ and Casey et al. ${ }^{9}$ further demonstrated that CNT interacted, with a variable degree, with all the cell viability dyes they used in their study (i.e. Commassie Blue, Alamar Blue, Neutral Red, MTT and WST-1), arguing for the inadequacy of these assays to report CNT cytotoxicity. Similarly, Monteiro-Riviere et al. ${ }^{10}$ tested a panel of six classical dye-based assays and found that most of them produced erroneous results.

Similarly, it was observed that nanomaterials could interfere with classical genotoxicity assays (micronucleus or comet assays), oxidative stress assay (measurement of reactive oxygen species), or with inflammatory response assays (evaluation of the production of various cytokines or mediators) ${ }^{11-15}$. As an example, a previous study from our group focused on the artifacts occurring during the assessment of TNF $\alpha$ production after a contact between macrophages and boehmite nanoparticles ${ }^{16}$. It was observed that 6 wt. $\%$ of TNF $\alpha$ adsorbed on the walls of 96-well plates, and $13 \mathrm{wt} . \%$ adsorbed on the boehmite surface. This suggests that data from this assay can be underestimated.

The interference in biological assays are far from being systematically taken into consideration, as reported by Ong et al.6. In this paper a review of the existing nanotoxicology literature was carried out to assess whether appropriate assay controls were performed to ensure that nanomaterials did not interfere with the assays and that the results of these tests were accurate. It turned out that in $2010,84 \%$ of papers in the nanotoxicology field used at least one type of colorimetric or fluorescence assay and of these, $95 \%$ were published without reporting controls for nanomaterial interferences. In 2012, notwithstanding the increasing number of published reports on nanomaterial-assay interferences, this rate had only marginally improved: $90 \%$ of papers were published without some type of assay control. This may explain the lack of consistency of some results reported in the literature.

These interferences may be so important that they can make some commonly used tests totally irrelevant to report nanomaterials toxicity $7,9,8,17$. But as the nature and intensity of 
artifacts also depend on the nanomaterial type, many authors recommend that interferences should be carefully assessed for each nanomaterial type in an acellular system. In other words, the suitability of the assay for assessing nanomaterial toxicity should be examined case by case. Only this approach will allow selecting the optimal assay for different types of nanomaterials $4,10,18$.

In this context, we focused our attention on the cytotoxicity of CNT, in particular the loss of membrane integrity was evaluated by the commonly used released lactate dehydrogenase (LDH) quantification. The principle of this toxicological assay is illustrated in Figure 1.
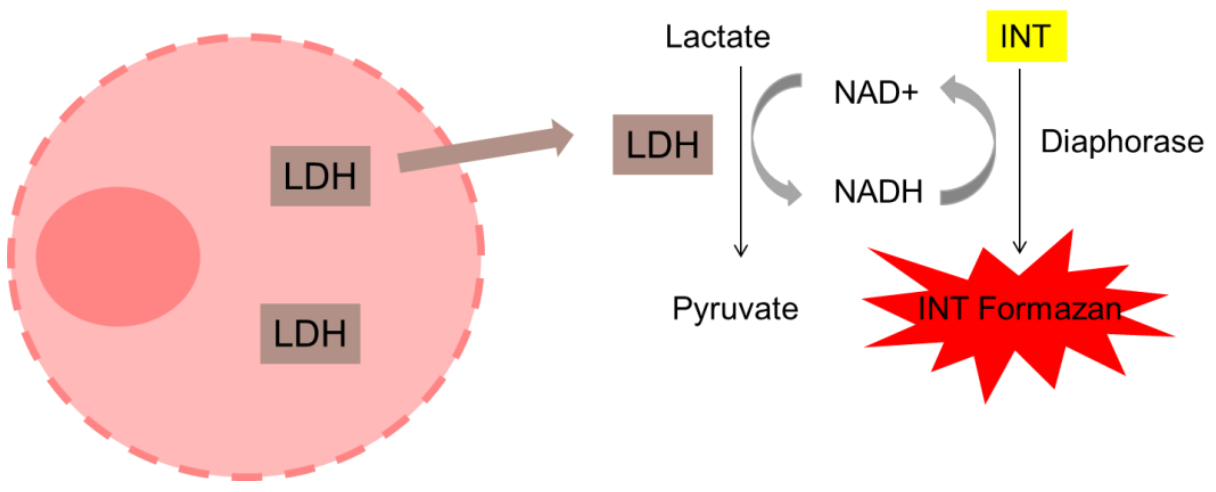

Figure 1: Schematic representation of the principle of the LDH release assay. The LDH assay evaluates the membrane integrity of cells by measuring the concentration of the cytosolic LDH enzyme leaked in the extracellular medium in case of membrane damage.

Briefly, the LDH released from cells in the culture supernatant catalyzes the hydrolysis of lactate in pyruvate. This reaction is accompanied by the stoichiometrical reduction of Nicotinamide Adenine Dinucleotide $\left(\mathrm{NAD}^{+}\right)$in $\mathrm{NADH}$. This latter is used as a limiting reagent in a second reaction catalyzed by the diaphorase. A tetrazolium salt: INT (2-(4iodophenyl)-3-(4-nitrophenyl)-5-phenyl-2H-tertrazolium) is transformed in red formazan which formation can be spectrophotometrically quantified at $490 \mathrm{~nm}$ and which amount is proportional to that of $\mathrm{LDH}$ present in the medium. But in this assay, artifacts can be due to 
three parameters: 1) the CNT intrinsic absorbance, 2) the interactions between CNT and reagents from the assay or 3) the interactions between CNT and LDH.

The aim of this study was to evaluate qualitatively and quantitatively the interferences occurring between the CNT and the LDH assay. To that purpose, experiments in cell free conditions were performed, and from the data obtained the adsorption isotherm of LDH on CNT was studied. This allowed taking into account the interferences occurring in the assay and consequently correcting results from cellular experiments to get more accurate data and lead to proper conclusions on the cytotoxicity of CNT.

\section{Experimental:}

- CNT:

Multi-walled carbon nanotubes (MWCNT, NC7000) were provided by Nanocyl (Sambreville, Belgium). They measured $9.5 \mathrm{~nm}$ in diameter and $1.5 \mu \mathrm{m}$ in length (according to the manufacturer). CNT were dispersed in culture medium: Dubelcco's modified Eagle's medium (DMEM, Invitrogen) complemented with 10\% fetal calf serum (FCS, Invitrogen), 1\% penicillin-streptomycin (penicillin 10,000 U.mL-1, streptomycin $10 \mathrm{mg} \cdot \mathrm{mL}^{-1}$, Sigma-Aldrich). Concentrations from 15 to $120 \mu \mathrm{g} \cdot \mathrm{mL}^{-1}$ were used. A sonication was carried out until the complete dispersion of the suspension ( $5 \mathrm{~min}, 30 \%, 3 \mathrm{~mm}$ probe, Branson Sonifier S-450D). The dispersion and suspension stability were established by measuring zeta potential and particle size distribution by means of the light scattering technique (Zetasier Nano ZS). After dilutions, the suspensions were kept at $4^{\circ} \mathrm{C}$ and used in the following $48 \mathrm{~h}$.

- LDH assay in cell free conditions:

The LDH assay was performed using the CytoTox- $96^{\circledR}$ non-radioactive cytotoxicity assay kit (Promega). Within this kit a LDH solution was provided as a positive control solution. This LDH was extracted from bovine heart and its initial concentration was $0.8 \mathrm{U} \mu \mathrm{L}^{-1}$. $\mathrm{U}$ is the unit of enzymatic activity, defining the speed of consumption of a substrate by unit of time. 
For example, in the LDH case, $1 \mathrm{U}$ corresponds to the oxidation of $1 \mathrm{mM} \cdot \mathrm{min}^{-1}$ of NADH. A protocol to assess the interferences in the determination of the LDH release was established in cell free conditions. The absorbance of solutions containing LDH alone (concentrations from 0.00005 to $0.004 \mathrm{U}_{\mu} \mathrm{L}^{-1}$ ), $\mathrm{CNT}$ alone (concentrations from 15 to $120 \mu \mathrm{g} \cdot \mathrm{mL}^{-1}$ ) or a mixture of LDH and CNT was assessed using a microplate reader (Multiskan GO, Thermo Scientific) set at $450 \mathrm{~nm}$. Negative controls were also included (solutions with no LDH or no CNT).

- LDH assay in cellular conditions:

The RAW264.7 cell line, commonly used in nanotoxicology studies was provided by ATCC Cell Biology Collection (Promochem LGC) and derived from mice peritoneal macrophages transformed by AMLV (Abelson Murine Leukemia Virus). Cells were cultured in complemented DMEM and incubated at $37^{\circ} \mathrm{C}$ under a $5 \%$ carbon dioxide humidified atmosphere. Cells were seeded in a 96-well plate (100,000 cells/well) and were incubated for 24h with CNT (concentration ranging from 15 to $120 \mu \mathrm{g} \cdot \mathrm{mL}^{-1}$ ). Cell viability was then evaluated by quantifying the LDH released in culture supernatant from cells with damaged membranes, using the CytoTox- $96^{\circledR}$ non-radioactive cytotoxicity assay according to the manufacturer's instructions. Detection was performed using a microplate reader (Multiskan GO, Thermo Scientific) at $450 \mathrm{~nm}$. The activity of the released LDH was reported as a percentage of the total cellular LDH (measured after the complete lysis of control cells corresponding at the maximal amount that can be released by cells, therefore $100 \%$ ).

- Expression of the results and statistical analysis:

Results are expressed as means of 3 independent experiments, with each measure performed in triplicate. Statistical analysis was carried out using a Student test. Difference was declared significant when $\mathrm{p}<0.05$.

\section{$\underline{\text { Results: }}$}

Cell free condition assays: 
The absorbance at $450 \mathrm{~nm}$ of solutions containing various concentrations of LDH (from 0 to 0.004 U. $\mu \mathrm{L}^{-1}$ ) was measured in presence of various concentrations of CNT (from 0 to 120 $\mu$ g.mL-1). Results are reported in Figure 2.

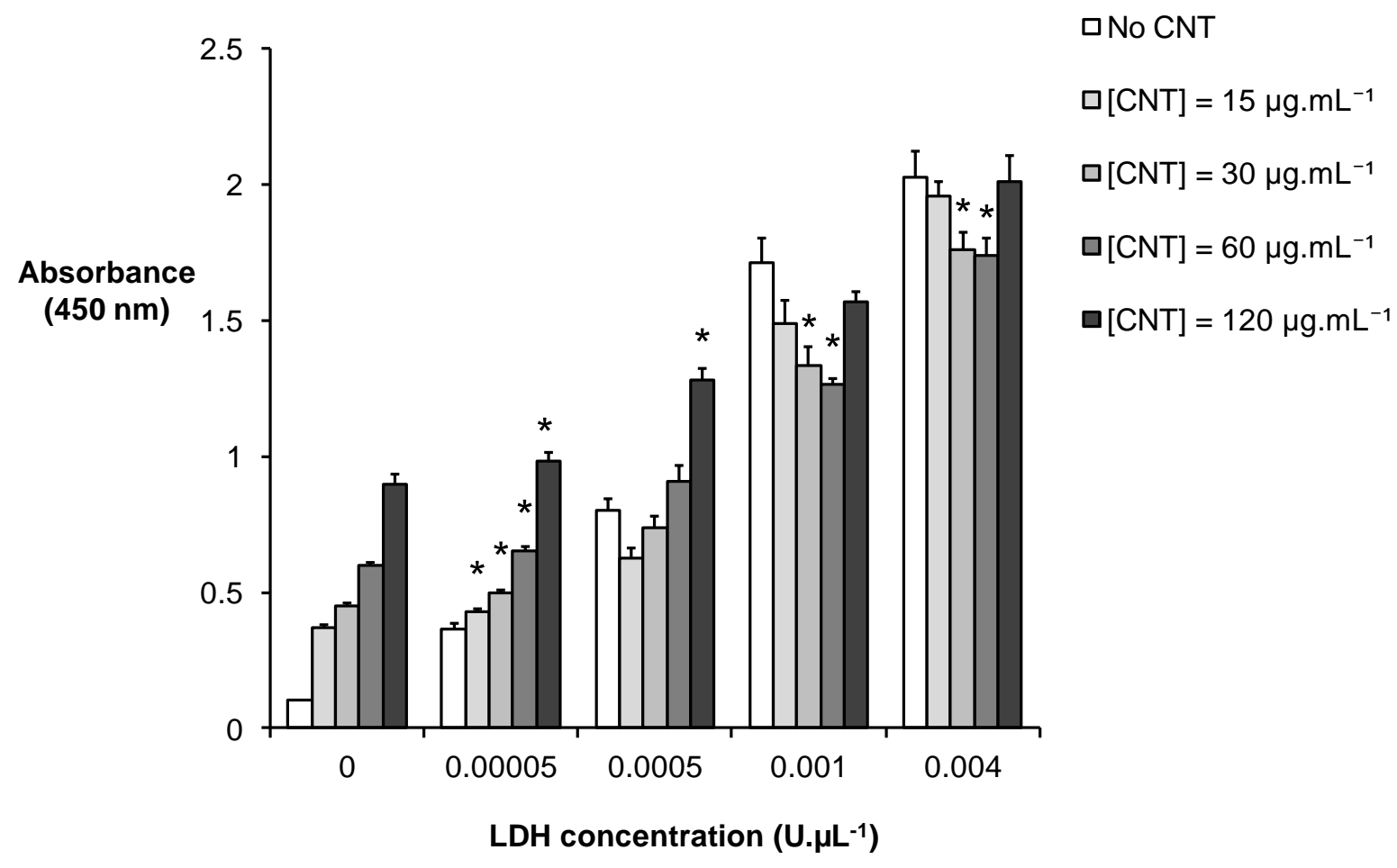

Figure 2: Absorbance at $450 \mathrm{~nm}$ of solutions containing CNT and LDH (acellular condition). * $\mathrm{p}<0.05$ as determined by a Student test.

It clearly appeared that CNT alone induced a dose-dependent increase in absorbance at 450 $\mathrm{nm}$. The addition of low doses of $\mathrm{LDH}\left(0.00005\right.$ or $\left.0.0005 \mathrm{U} \mu \mathrm{L}^{-1}\right)$ did not influence this increase. But with higher concentrations of $\mathrm{LDH}\left(0.001\right.$ or $\left.0.004 \mathrm{U}_{\mu} \mu \mathrm{L}^{-1}\right)$ a peculiar behavior was observed: solutions containing 30 or $60 \mu \mathrm{g} \cdot \mathrm{mL}^{-1} \mathrm{CNT}$ exhibited an absorbance significantly lower than that containing 15 or $120 \mu \mathrm{g} \cdot \mathrm{mL}^{-1}$ and even than that without CNT. From these observations three assumptions could be made: 
1. An optical artifact occurred, induced by the partial extinction of light due to the diffusing nature of CNT.

2. An artifact due to a variation of the LDH concentration consecutive to its adsorption at the CNT surface might be implicated.

3. A combination of the two above-mentioned artifacts occurred.

To test the first hypothesis, the absorbance of CNT alone was further investigated. CNT were diluted either in PBS (Phosphate Buffered Saline) or in culture medium in presence of the reagents from the assay, and the absorbance was measured as indicated in Figure 3.

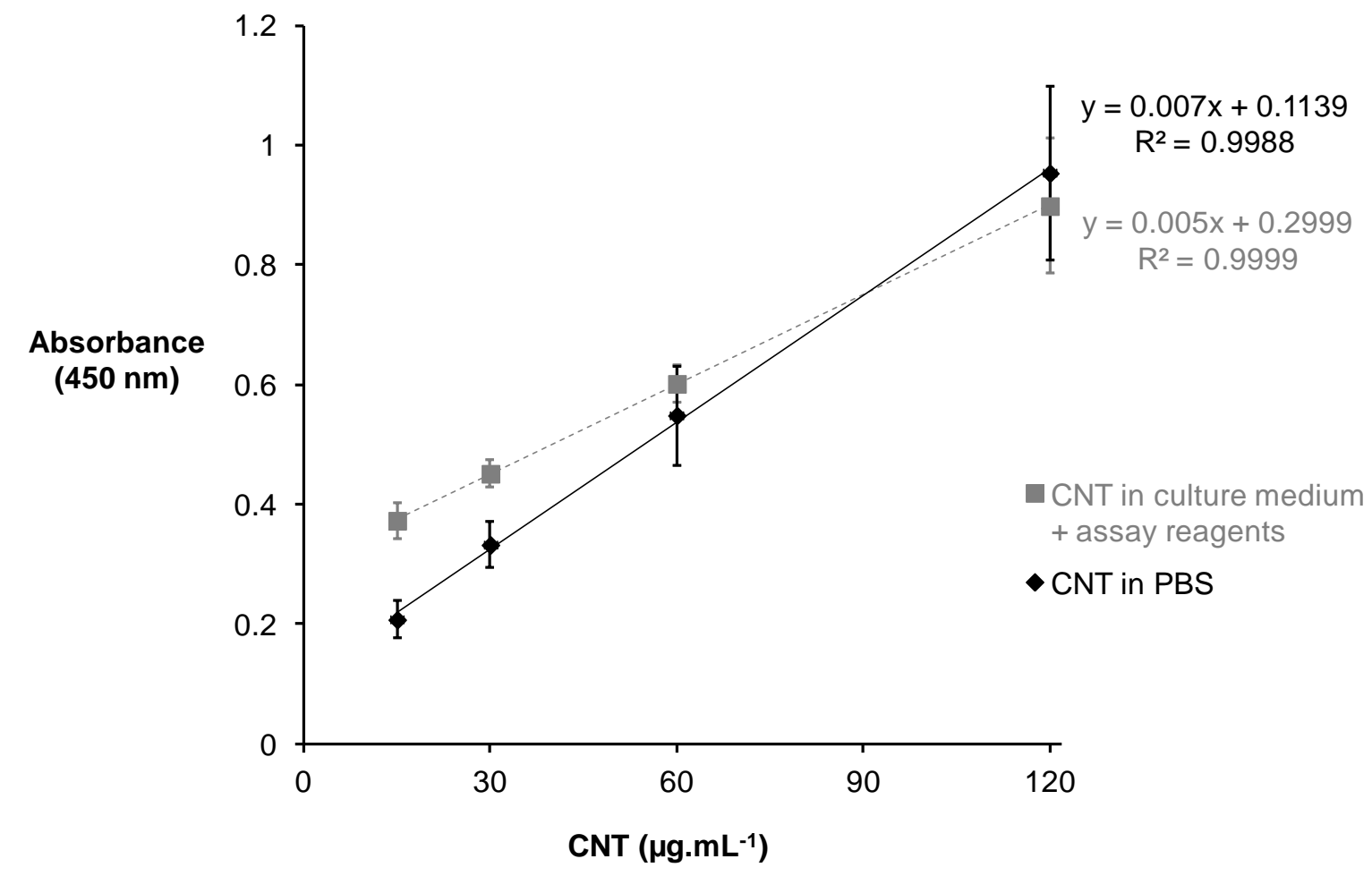

Figure 3: Absorbance at $450 \mathrm{~nm}$ of $\mathrm{CNT}$ diluted in culture medium in presence of the kit reagents or diluted in an equivalent volume of PBS.

An intrinsic dose-dependent absorbance of CNT was clearly observed when CNT were diluted in PBS. At the lowest CNT concentrations, a slight additive absorbance was due to 
the culture medium and the assay kit reagents. This result clearly demonstrated an optical artifact due to the presence of CNT.

\section{$>$ Quantification of the interferences:}

The intrinsic ability of CNT to interfere with the LDH assay through their diffusive nature can thus lead to biased measures. Indeed, CNT can diffuse the incident light and induce a partial extinction of the signal. The evolution of the absorbance only due to the presence of CNT at low concentrations (without the presence of LDH) follows a linear relationship, respecting the Beer-Lambert law:

$$
\mathrm{A}=\varepsilon \mathrm{lC}
$$

Equation 1

where A represents the absorbance, $\varepsilon$ the molar extinction coefficient $\left(\mathrm{L} \cdot \mathrm{mol}^{-1} \cdot \mathrm{cm}^{-1}\right), 1$ the length of the optical path travelled by the light beam $(\mathrm{cm})$ and $\mathrm{C}$ the concentration (mol. $\left.\mathrm{L}^{-1}\right)$. Similarly, the absorbance of LDH alone follows a linear relationship $(y=942.1 x+0.3239$; $\mathrm{R}^{2}=0.9997$, see Supplementary Figure 1).

In theory, the absorbance of a mixture of two solutions is equivalent to the sum of the absorbance of each solution. In other words, we should observe that $A_{C N T+L D H}=A_{L D H}+A_{C N T}$. However, this was not the case: the absorbance of the solution containing both CNT and a known concentration of LDH was lower than that of the control solution containing only $\mathrm{LDH}$, without CNT. An example (for the $0.001 \mathrm{U} . \mu \mathrm{L}^{-1} \mathrm{LDH}$ concentration) is detailed in Figure 4 but the same conclusion was reached for each LDH concentration as reported in Supplementary Figure 2. 


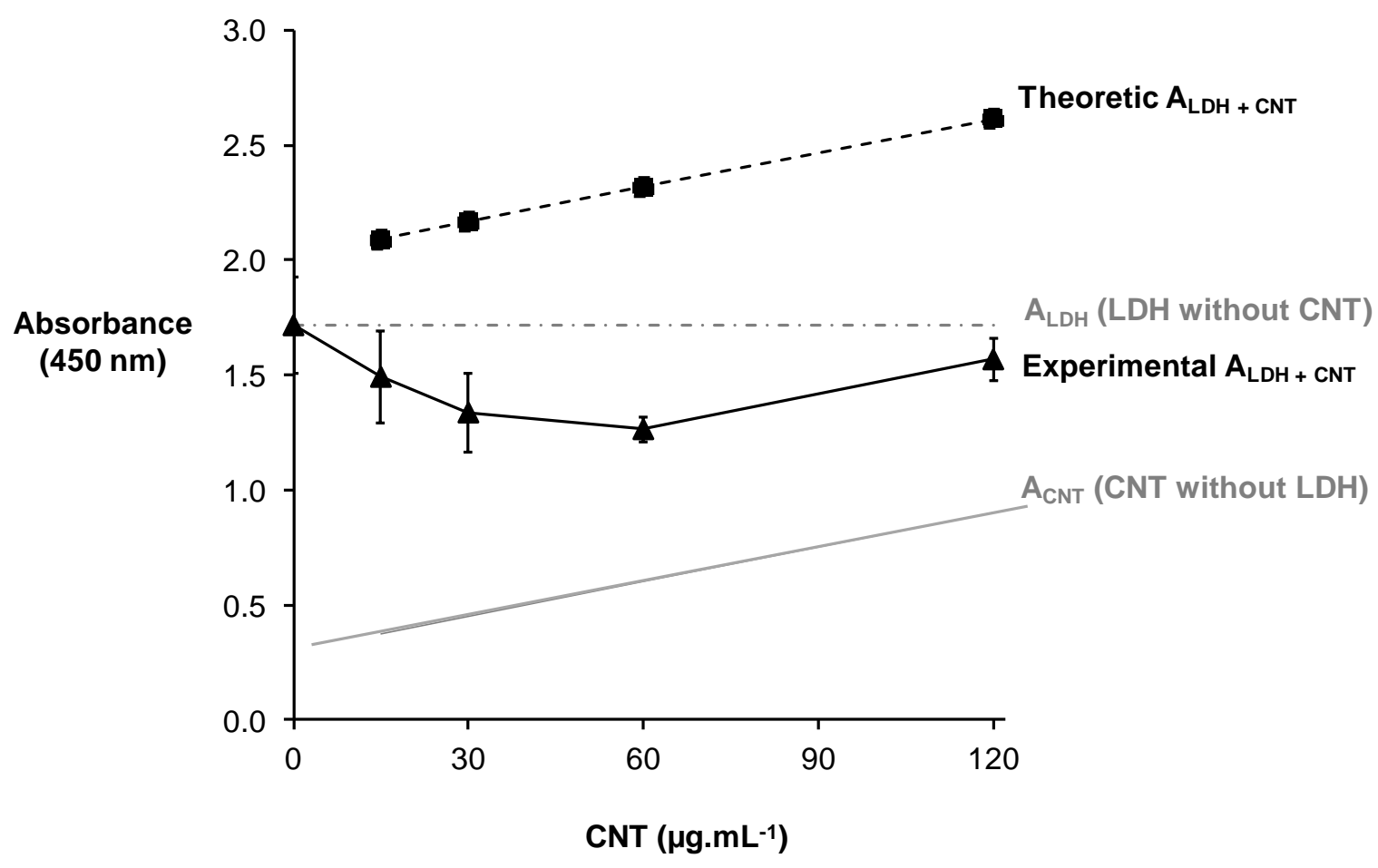

Figure 4: Difference between the theoretical and experimental absorbance of a LDH solution (concentrated $0.001 \mathrm{U} . \mu \mathrm{L}^{-1}$ ) with various concentrations of $\mathrm{CNT}$.

This may suggest that between the assumptions previously made on the nature of the interferences (optical artifact induced by the partial extinction of light due to the diffusing nature of $\mathrm{CNT}$ or an artifact due to a variation of the $\mathrm{LDH}$ concentration consecutive to its adsorption at the CNT surface), the two occurred simultaneously. A part of the LDH initially introduced in the solution absorbed at the CNT surface, thus decreasing the amount of free $\mathrm{LDH}$ available to catalyze the conversion of lactate in pyruvate and therefore decreasing the amount of formed INT formazan.

From this hypothesis and based on the absorbance of the CNT and LDH solutions measured either separately or in mixture, it was possible to calculate the amount of LDH free in solution depending on the CNT concentration as determined by the following equation and as reported by Figure 5A. 


$$
\mathrm{n}_{\text {free LDH }}=\frac{\mathrm{n}_{\text {theoretic LDH }}}{\mathrm{A}_{\text {theoretic LDH }}} \times\left(\mathrm{A}_{\mathrm{LDH}+\mathrm{CNT}}-\mathrm{A}_{\mathrm{CNT}}\right)
$$

Equation 2

where $\eta_{\text {free LDH }}$ represents the amount of LDH free in solution (mol), $\eta_{\text {theoretic LDH }}$ is the theoretic amount of LDH in solution (i.e. the introduced amount of LDH, in mol), $\mathrm{A}_{\text {theoretic LDH }}$ is the awaited absorbance of the LDH solution (calculated by the Beer-Lambert law, Equation 1), $\mathrm{A}_{\mathrm{LDH}+\mathrm{CNT}}$ the measured absorbance of the solution containing both $\mathrm{LDH}$ and CNT and $\mathrm{A}_{\mathrm{CNT}}$ the absorbance of the solution with CNT only.

The amount of LDH adsorbed on the CNT can then be deduced simply by subtracting the amount of LDH free in solution (and that has formed the colored INT formazan) from the initially introduced LDH, as reported in Figure 5B.

A)

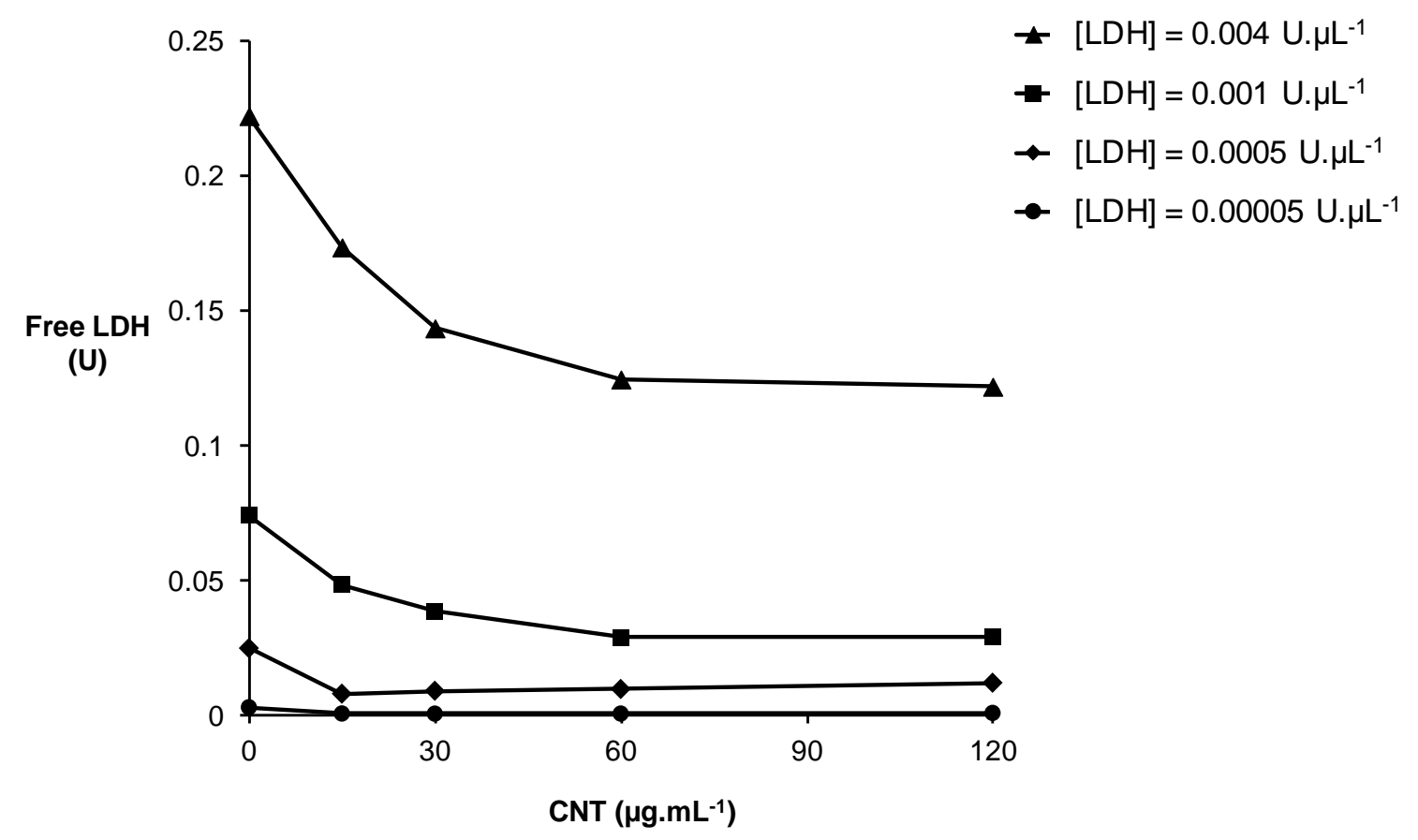


B)

$\rightarrow[\mathrm{LDH}]=0.004$ U. $\mu \mathrm{L}^{-1}$

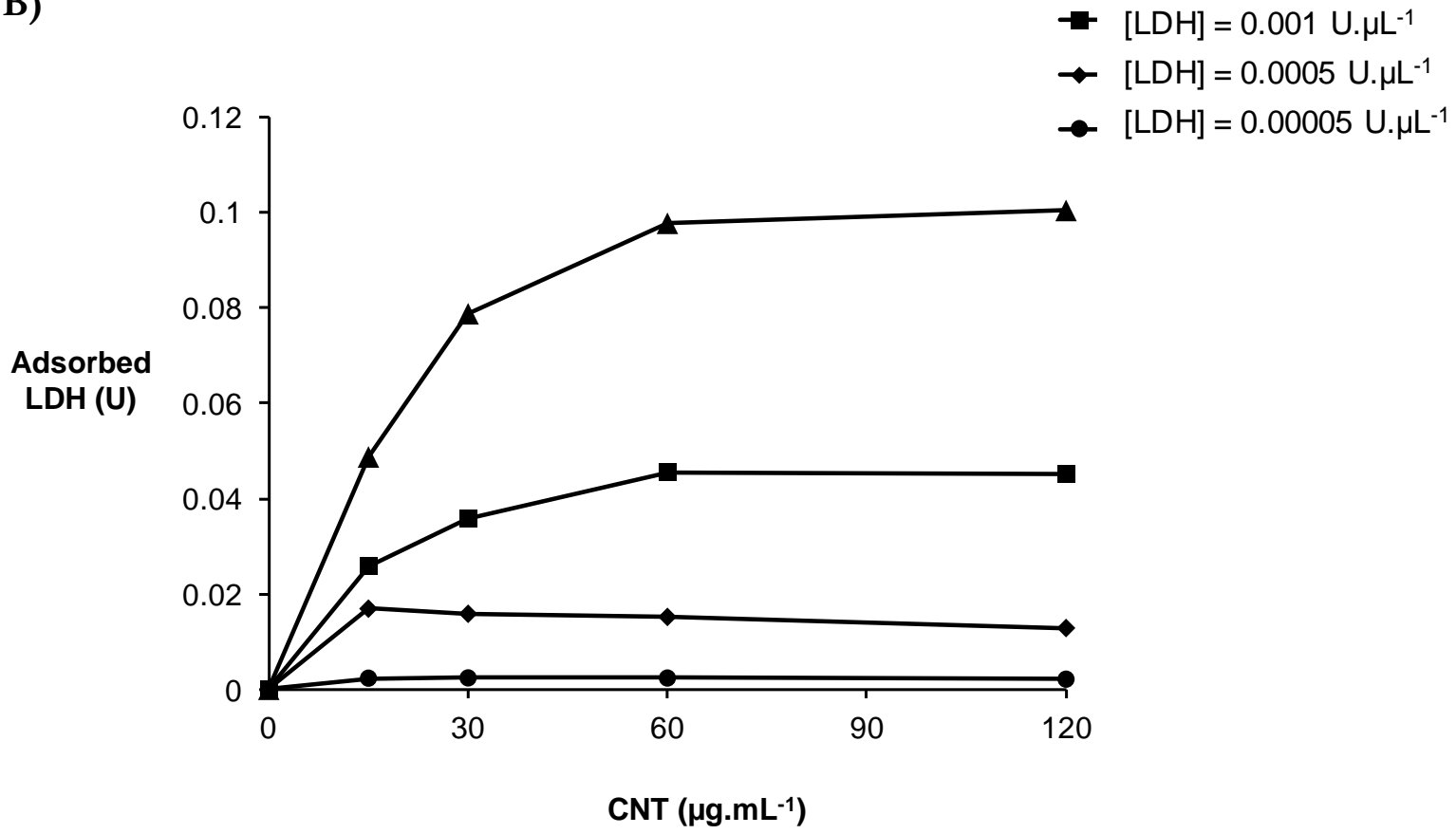

Figure 5: A) Free LDH depending on the CNT concentration calculated for different LDH concentrations (concentration from 0.00005 to 0.004 U. $\mu \mathrm{L}^{-1}$ ). B) LDH adsorbed on CNT calculated for different LDH concentrations (concentration from 0.00005 to $0.004 \mathrm{U}_{\mathrm{H}} \mathrm{L}^{-1}$ ).

The thermodynamic equilibrium was reached leading to the determination of the adsorption isotherm. Figure 6 represents this adsorption isotherm, i.e. the amount of adsorbed LDH by mass of CNT depending on the amount of free LDH reported by mass of CNT. The same conclusion was reached when the data were expressed depending on CNT surface instead of CNT mass (Supplementary Figure 3). The results confirmed the existence of a bias due to the adsorption of $\mathrm{LDH}$ on $\mathrm{CNT}$, providing an explanation for the difference observed between the theoretical absorbance of a mixture of CNT and LDH and the absorbance experimentally measured (Figure 4). 


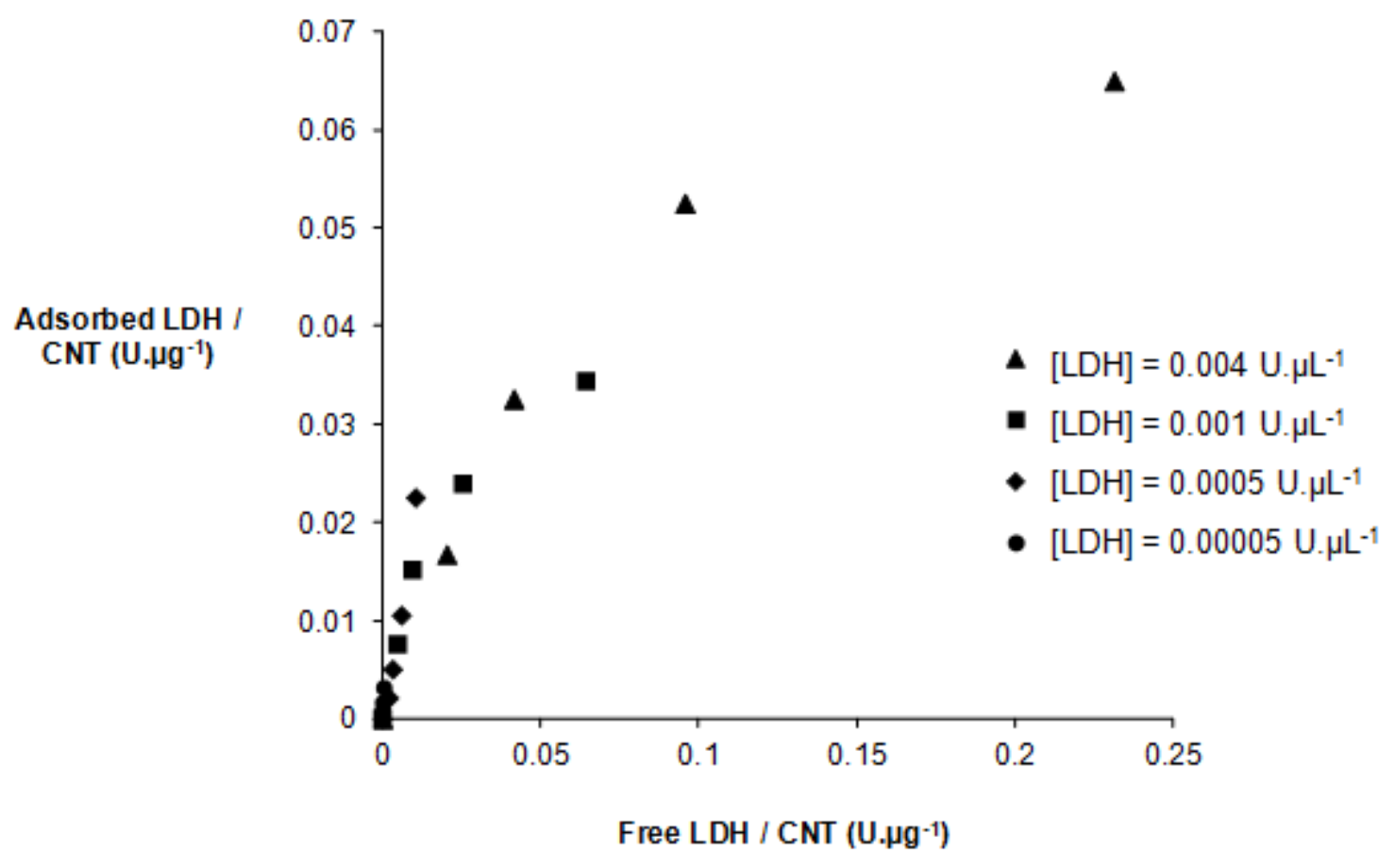

Figure 6: Adsorption isotherm of LDH on CNT for different LDH concentrations. Results are reported by mass (in $\mu \mathrm{g}$ ) of CNT.

\section{Modeling of the adsorption of LDH on CNT:}

The adsorption of proteins on a surface are usually modeled using the Langmuir model. It initially modeled the reversible adsorption of a gas molecules monolayer on a surface. The following equation gives the mathematical model for the adsorption of a protein on a surface:

$$
\mathrm{n}_{\mathrm{ads}}=\frac{\mathrm{n}_{\mathrm{eq}} \times \mathrm{K}_{\mathrm{ads}} \times \mathrm{n}_{\text {free }}}{1+\mathrm{K}_{\mathrm{ads}} \times \mathrm{n}_{\text {free }}}
$$

Equation 3

where $\mathrm{n}_{\text {ads }}$ corresponds to the amount of proteins adsorbed by mass of solid, $\mathrm{n}_{\text {eq }}$ the maximal amount of proteins adsorbed by mass of solid, $\mathrm{K}_{\mathrm{ads}}$ the adsorption constant, $\mathrm{n}_{\text {free }}$ the amount of free protein.

Here, the equation is adapted to normalize the data by the mass of CNT: 


$$
\frac{\mathrm{n}_{\mathrm{ads}}}{\mathrm{m}_{\mathrm{CNT}}}=\frac{\frac{\mathrm{n}_{\mathrm{eq}}}{\mathrm{m}_{\mathrm{CNT}}} \times \mathrm{K}_{\mathrm{ads}} \times \mathrm{n}_{\text {free }}}{1+\mathrm{K}_{\mathrm{ads}} \times \mathrm{n}_{\text {free }}}
$$

Equation 4

The equation is rearranged assuming that $\propto=\mathrm{K}_{\mathrm{ads}} \times \mathrm{m}_{\mathrm{CNT}}$. Consequently, $\mathrm{K}_{\mathrm{ads}}=\frac{\propto}{\mathrm{m}_{\mathrm{CNT}}}$. By replacing this constant in the previous equation, the following expression of the Langmuir equation is obtained:

$$
\frac{\mathrm{n}_{\mathrm{ads}}}{\mathrm{m}_{\mathrm{CNT}}}=\frac{\frac{\mathrm{n}_{\mathrm{eq}}}{\mathrm{m}_{\mathrm{CNT}}} \times \propto \times \frac{\mathrm{n}_{\text {free }}}{\mathrm{m}_{\mathrm{CNT}}}}{1+\propto \times \frac{\mathrm{n}_{\text {free }}}{\mathrm{m}_{\mathrm{CNT}}}}
$$

Equation 5

$\propto$ and $\mathrm{n}_{\mathrm{eq}}$ are determined using a linear regression:

$$
\frac{\mathrm{n}_{\text {free }} / \mathrm{m}_{\mathrm{CNT}}}{\mathrm{n}_{\mathrm{ads}} / \mathrm{m}_{\mathrm{CNT}}}=\frac{1}{\mathrm{n}_{\mathrm{eq}} / \mathrm{m}_{\mathrm{CNT}} \times \propto}+\frac{\mathrm{n}_{\text {free }} / \mathrm{m}_{\mathrm{CNT}}}{\mathrm{n}_{\mathrm{eq}} / \mathrm{m}_{\mathrm{CNT}}}
$$

Equation 6

From the plot, reported in Supplementary Figure 4 , it was determined that $\frac{1}{\mathrm{n}_{\mathrm{eq}} / \mathrm{m}_{\mathrm{CNT}}}=$

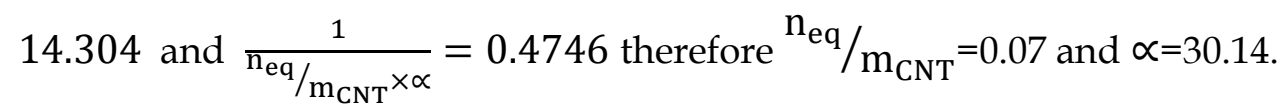

This fitted with the adsorption isotherm reported in Figure 6, as illustrated in Figure 7. 


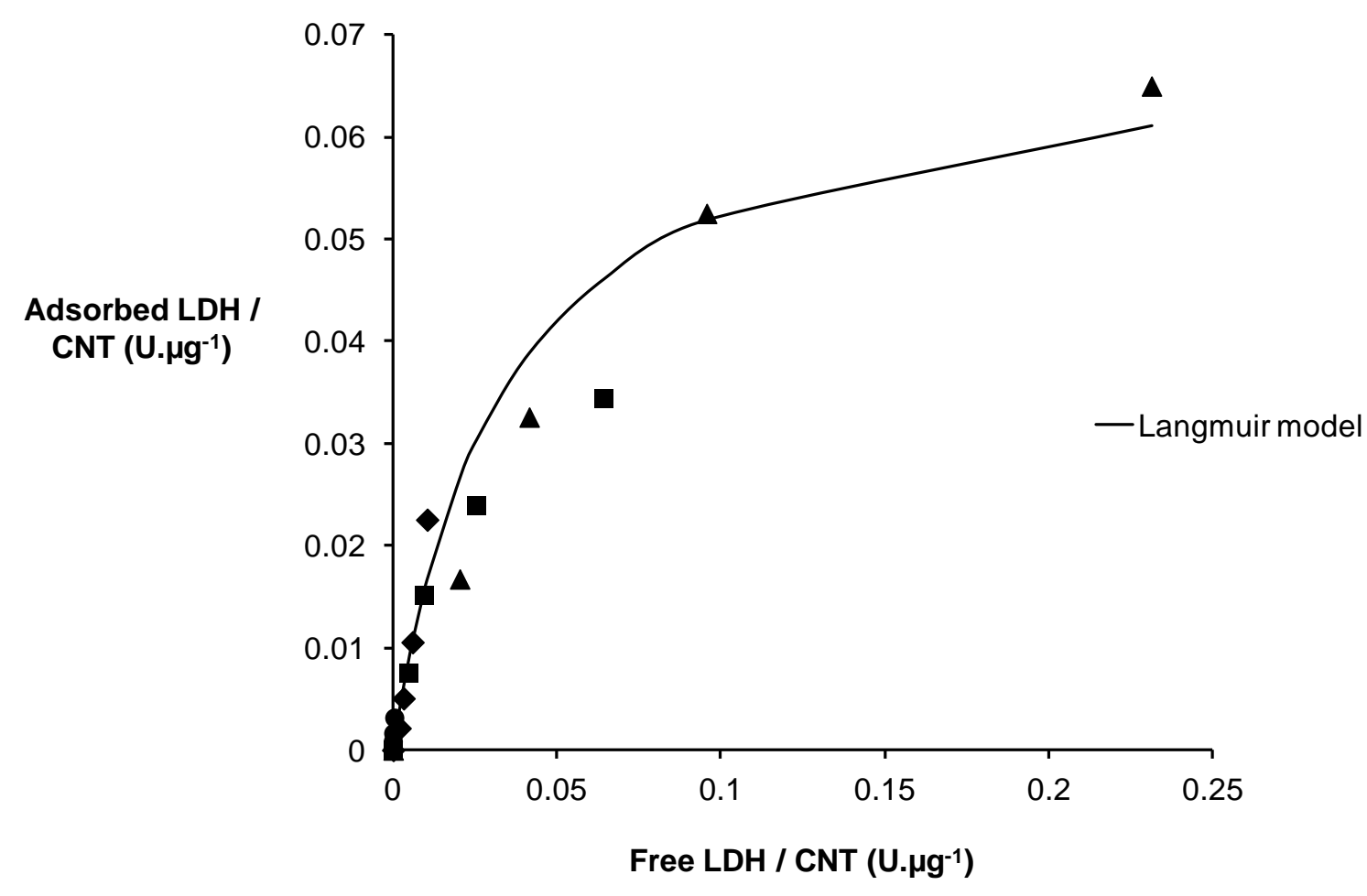

Figure 7: Adsorption isotherm of LDH on CNT fitting with the Langmuir model.

Rigorously, it should be specified that although the Langmuir model proposed allows a satisfactory mathematical fit of the adsorption data, the basic assumptions of the model were not fully verified. Indeed, we did not check if all conditions implied in the Langmuir model were met (e.g. the reversibility of adsorption, the monolayer coverage, the site-binding model were not demonstrated). But the understanding of the adsorption mechanism was beyond the scope of this study and it was observed that our experimental data mathematically fitted best with the Langmuir model. Moreover, other models (Hasley, Temkin-Pyzhev, Freundlich) were tested but the results were not satisfactory as illustrated in Supplementary Figure 5.

Finally, the actual concentration of LDH in solution can be calculated by combining the following equations:

$$
\mathrm{n}_{\mathrm{LDH}}=\mathrm{n}_{\text {free }}+\mathrm{n}_{\mathrm{ads}}
$$




$$
\begin{gathered}
\mathrm{n}_{\mathrm{LDH}}=\mathrm{V} \times \mathrm{C}_{\text {free }}+\frac{\mathrm{n}_{\mathrm{eq}} \times \mathrm{K}_{\mathrm{ads}} \times \mathrm{V} \times \mathrm{C}_{\text {free }}}{1+\mathrm{K}_{\mathrm{ads}} \times \mathrm{V} \times \mathrm{C}_{\text {free }}} \\
\mathrm{C}_{\mathrm{LDH}}=\frac{\mathrm{n}_{\mathrm{LDH}}}{\mathrm{V}}=\mathrm{C}_{\text {free }}+\frac{\mathrm{n}_{\mathrm{eq}} \times \mathrm{K}_{\mathrm{ads}} \times \mathrm{C}_{\text {free }}}{1+\mathrm{K}_{\mathrm{ads}} \times \mathrm{V} \times \mathrm{C}_{\text {free }}} \\
\mathrm{C}_{\mathrm{LDH}}=\frac{\mathrm{A}_{\mathrm{LDH}+\mathrm{CNT}}-\mathrm{A}_{\mathrm{CNT}}}{\varepsilon_{\mathrm{LDH}} \times \mathrm{l}}+\frac{\mathrm{n}_{\mathrm{eq}} \times \mathrm{K}_{\mathrm{ads}} \times\left(\mathrm{A}_{\mathrm{LDH}+\mathrm{CNT}}-\mathrm{A}_{\mathrm{CNT}}\right)}{\left(\varepsilon_{\mathrm{LDH}} \times \mathrm{l}\right) \times\left(1+\mathrm{K}_{\mathrm{ads}} \times \mathrm{V} \times \frac{\left.\mathrm{A}_{\mathrm{LDH}+\mathrm{CNT}}-\mathrm{A}_{\mathrm{CNT}}\right)}{\varepsilon_{\mathrm{LDH}} \times \mathrm{l}}\right)}
\end{gathered}
$$

with $\mathrm{K}_{\mathrm{ads}}=\frac{\alpha}{\mathrm{m}_{\mathrm{CNT}}}$ and keeping in mind that $\mathrm{n}_{\mathrm{eq}} / \mathrm{m}_{\mathrm{CNT}}$ was already calculated:

$$
\mathrm{C}_{\mathrm{LDH}}=\frac{\mathrm{A}_{\mathrm{LDH}+\mathrm{CNT}}-\mathrm{A}_{\mathrm{CNT}}}{\varepsilon_{\mathrm{LDH}} \times \mathrm{l}}+\frac{\mathrm{n}_{\mathrm{eq}} \times \frac{\propto}{\mathrm{m}_{\mathrm{CNT}}} \times\left(\mathrm{A}_{\mathrm{LDH}+\mathrm{CNT}}-\mathrm{A}_{\mathrm{CNT}}\right)}{\varepsilon_{\mathrm{LDH}} \times \mathrm{l}+\frac{\propto}{\mathrm{m}_{\mathrm{CNT}}} \times \mathrm{V} \times\left(\mathrm{A}_{\mathrm{LDH}+\mathrm{CNT}}-\mathrm{A}_{\mathrm{CNT}}\right)} \quad \text { Equation } 7
$$

It is therefore possible to determine the actual $\mathrm{LDH}$ concentration in solution after the calculation of the adsorption constants as determined by a cell free assay.

\section{Correction of data from cellular assays:}

This approach was adopted to correct results from previous experiments, in which macrophages from the RAW264.7 cell line were incubated with CNT for 24 hours and the LDH release was assessed using the same assay to detect the membrane integrity loss ${ }^{19}$. Figure 8 compares the values before and after correction. The differences ranged from 9 to $12 \%$ depending on CNT concentration. Only the highest concentration of CNT triggered a LDH release significantly different from that of the control but the same conclusion was reached either with or without correction. Even though the correction did not change the 
conclusion of the assay in this particular case, it clearly appeared that data were underestimated. Results are more accurate and trustable after correction.

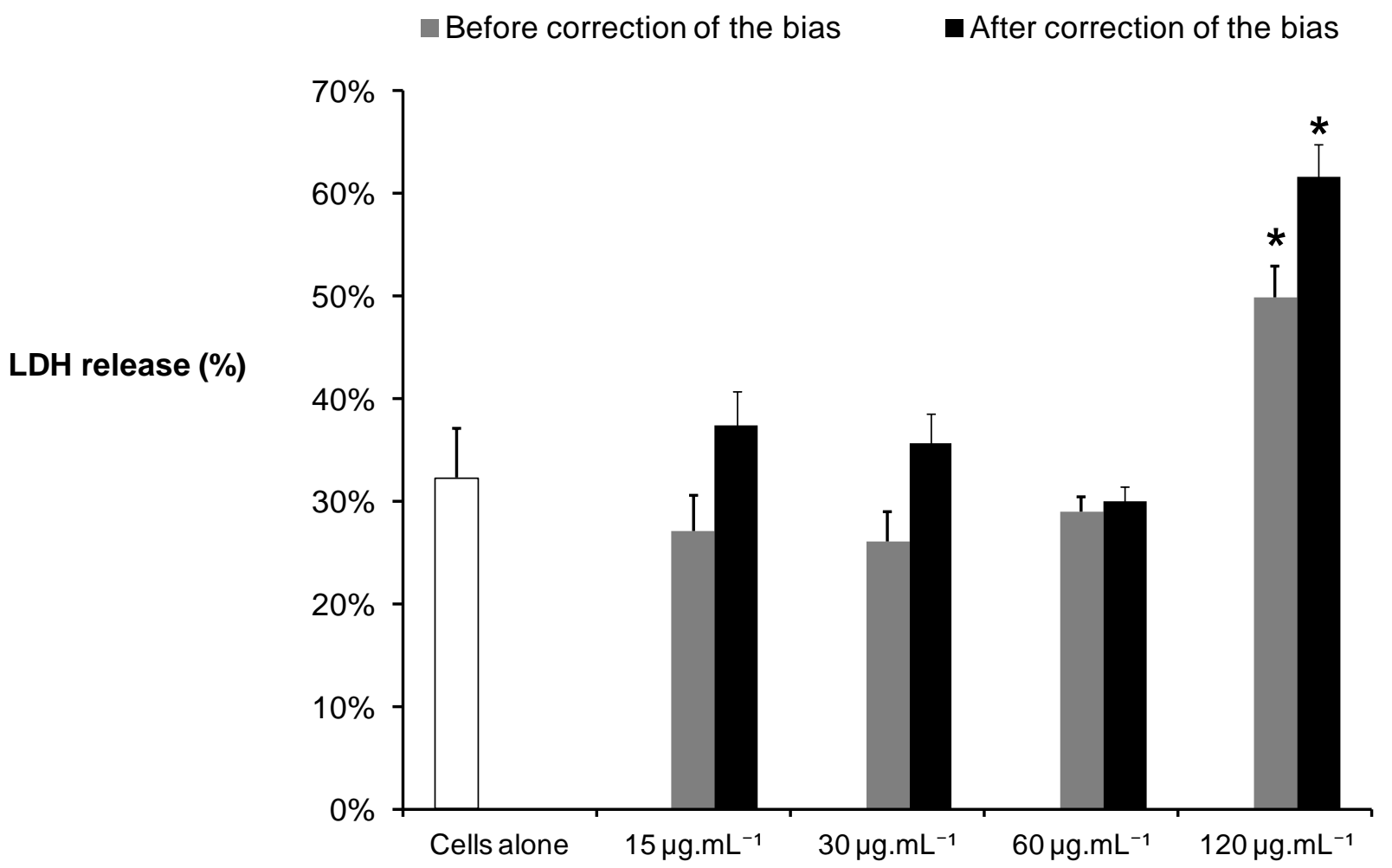

Figure 8: LDH release expressed as a percent of the positive control (lysed cells) determined after a 24h incubation of RAW264.7 macrophages with various concentrations of CNT. The white bar represents the negative control (cells incubated without CNT), grey bars represent the raw data from the assay and the black bars represent the results after correction of the bias due to the presence of CNT. * means significantly different from the negative control $(\mathrm{p}<0.05$, Student test $)$.

\section{Discussion:}

Current in vitro toxicity tests used for nanomaterial risk assessment rely on standard viability assays that were developed for chemicals or macro-scale substances and that are frequently based on absorbance or fluorescence measurements. However, nanomaterials display unique physicochemical properties that can interfere with or pose challenges to the use of classical 
toxicity assays ${ }^{3,17}$. They can even lead to false-positive or false-negative results resulting subsequently in misinterpretations. Nanomaterial interferences with toxicity assays should not be neglected as they have been reported for most spectroscopic analyses ${ }^{6}$.

Possible interactions from particles are: 1) particle optical properties that interfere with light absorption or fluorescence used for detection, 2) chemical reactions between the particles and assay compounds, and 3) adsorption of assay molecules to the particle surface 3,17 .

In this study focused on the cytotoxicity of CNT as determined by the LDH release assay, we clearly demonstrated an optical artifact (due to the intrinsic absorbance of the CNT) resulting in an over-estimation of the LDH release as well as a chemical bias (due to the adsorbance of $\mathrm{LDH}$ on the CNT) leading to an under-estimation of the LDH release. Therefore in this particular case the two kinds of artifacts seem to compensate and the final result has a poor impact on the conclusion of the toxicological assay as illustrated by the comparison of the results before and after correction of the bias (Figure 8). But it may not be always the case and the interferences should not be neglected but on the contrary should be carefully considered.

Our results are in agreement with those of Wang et al. ${ }^{20}$ who observed a decrease in the absorbance at $490 \mathrm{~nm}$ of $\mathrm{LDH}$ solutions with increasing CNT concentrations. Our observations are also concordant with those of Breznan at al. ${ }^{18}$ who, although using another detection system (the fluorescent resorufin), reported that CNT could decrease the fluorescence signal through optical interference. This effect was not surprising as CNT are highly optically dense materials that prevent transmitted/emitted light from reaching the detector as already reported by Oostingh et al. ${ }^{13}$. This quenching of fluorescence by CNT was also reported by others9,10 whereas other nanomaterials such as quantum dots or C60 fullerene did not interact with the resorufin fluorimetric assays ${ }^{18}$. Alternatively (and sometimes additionally) the bias could originate from a physical interaction between the fluorescent/colorimetric dye and the CNT. Indeed, it is now well admitted that 
nanomaterials, due to their large surface area, can physically adsorb the assay components (e.g. substrates, dyes...) or the molecule to dose ${ }^{17,21}$. In this case, nanomaterial characteristics (such as hydrophobicity, surface charge...) are expected to play an important role in the adsorption process ${ }^{5,17}$.

The lack of sensitivity and reliability of existing methods clearly argue for the urgent need for the development of alternative and validated assays, best adapted to nanomaterial specificities as supported by many authors $3,5,9,15,17,20,21$ or as demonstrated by international efforts to discuss and determine which protocols might be standardized ${ }^{15}$. Recently, some new methods and modified versions of pre-existing methods have been developed for assessing the toxicity of nanomaterials ${ }^{3}$. One strategy may be to limit the interferences. To that purpose, Ali-Boucetta et al.22 have chosen to assess the intracellular LDH instead of the extracellular LDH to avoid the interactions between CNT and the components used in the test. After incubation with cells, CNT are rinsed off from the supernatant and the impact on the absorbance measure should therefore be eliminated. Cells are then lysed, centrifuged, and the amount of $\mathrm{LDH}$ present in the supernatant is determined reflecting the relative amount of viable cells instead of the amount of damaged cells as determined with the classical LDH assay. However, this approach has some limitations for instance it is difficult to rinse off all $\mathrm{CNT}$, some remaining attached to cell membranes and some potentially uptaken in the cytoplasm ${ }^{10,17}$. It may therefore be technically difficult to assess the bias and potentially not completely reliable. Moreover, particle induced artifacts are still controversial, especially they are thought to depend on the type of CNT considered. This is why the systematic consideration of the interferences in the CNT cytotoxicity assays remains rare $^{6}$.

Another way to mitigate the interactions between nanomaterials and CNT consists in limiting nanomaterials concentrations below levels that interfere or by adding compounds such as FBS which can decrease the adsorption of cytokines to particles ${ }^{17}$. 
As an example of alternative method, Wang et al. ${ }^{20}$ propose a variant in the LDH assay, they recommend to measure absorbance at $580 \mathrm{~nm}$ instead of $490 \mathrm{~nm}$, as they observed that while the broad $490 \mathrm{~nm}$ absorbance peak was decreased in intensity with increasing CNT concentrations, the smaller absorbance peak at $580 \mathrm{~nm}$ also varied, but considerably less. Although reducing the bias, this solution remains imperfect as it does not eliminate the interferences.

Until methods that avoid nanoparticle interferences have been fully developed, it appears necessary to be very cautious when using usual cytotoxicity assays not specifically designed for nanomaterials. One should be aware of their limitations and should try to understand how nanomaterials might interfere in the toxicological assay and if it is possible should quantify these biases. Indeed, if the interference is well characterized for the exposure conditions, a correction factor may be applied to the results ${ }^{15,17}$. To that purpose the evaluation of adsorption isotherms may be useful. But, it should be kept in mind that the adsorption of LDH on CNT is very likely to depend on the CNT physico-chemical features, especially the structural defect rate and the surface chemistry. Thus, adsorption isotherms should be calculated for each type of CNT.

To summarize, most researchers are now aware of the nanomaterial interference issue and many of them have emitted recommendations:

- the compatibility of an assay must be verified for each type of nanomaterial, in other words, it must be checked that the nanoparticles under investigation do not interfere with a specific assay at the expected concentrations. And to that purpose relevant controls must be used $3,6-8,15,17,20,21$.

- if interferences are found to occur with an assay and if alternative systems are not available the interferences should be limited (for example by using low concentrations of nanomaterials as the highest the concentration, the greater probability of interferences). Alternatively, interferences should be carefully characterized to be taken into account. 
Artifacts should be quantitatively evaluated and a corrective factor may be applied to the data $6,17,18,20,21$.

- two or more independent test systems should be performed to validate the results before concluding on the nanomaterial toxicity $3,5,7,21$.

- new or adapted methods must be developed to get new standards for nanoparticle risk assessment $t^{5}$

\section{Conclusion:}

Interferences occur in the LDH assay due to the intrinsic absorbance of CNT on one hand and to the adsorption of LDH at the CNT surface on the other hand. Even if the final artifacts are low, a correction is necessary to be rigorous. Further investigations with other kinds of nanomaterials are required to better understand this phenomenon and to adapt the correction to each case.

\section{References:}

(1) Baughman, R. H.; Zakhidov, A. A.; de Heer, W. A. Carbon Nanotubes--the Route toward Applications. Science 2002, 297, 787-792.

(2) De Volder, M. F. L.; Tawfick, S. H.; Baughman, R. H.; Hart, A. J. Carbon Nanotubes: Present and Future Commercial Applications. Science 2013, 339, 535-539.

(3) Dhawan, A.; Sharma, V. Toxicity Assessment of Nanomaterials: Methods and Challenges. Anal. Bioanal. Chem. 2010, 398, 589-605.

(4) Han, X.; Gelein, R.; Corson, N.; Wade-Mercer, P.; Jiang, J.; Biswas, P.; Finkelstein, J. N.; Elder, A.; Oberdörster, G. Validation of an LDH Assay for Assessing Nanoparticle Toxicity. Toxicology 2011, 287, 99-104. 
(5) Kroll, A.; Pillukat, M. H.; Hahn, D.; Schnekenburger, J. Current in Vitro Methods in Nanoparticle Risk Assessment: Limitations and Challenges. Eur. J. Pharm. Biopharm. Off. J. Arbeitsgemeinschaft Für Pharm. Verfahrenstechnik EV 2009, 72, 370-377.

(6) Ong, K. J.; MacCormack, T. J.; Clark, R. J.; Ede, J. D.; Ortega, V. A.; Felix, L. C.; Dang, M. K. M.; Ma, G.; Fenniri, H.; Veinot, J. G. C.; et al. Widespread Nanoparticle-Assay Interference: Implications for Nanotoxicity Testing. PloS One 2014, 9, e90650.

(7) Wörle-Knirsch, J. M.; Pulskamp, K.; Krug, H. F. Oops They Did It Again! Carbon Nanotubes Hoax Scientists in Viability Assays. Nano Lett. 2006, 6, 1261-1268.

(8) Belyanskaya, L.; Manser, P.; Spohn, P.; Bruinink, A.; Wick, P. The Reliability and Limits of the MTT Reduction Assay for Carbon Nanotubes-cell Interaction. Carbon $2007,45,2643-2648$.

(9) Casey, A.; Herzog, E.; Davoren, M.; Lyng, F. M.; Byrne, H. J.; Chambers, G. Spectroscopic Analysis Confirms the Interactions between Single Walled Carbon Nanotubes and Various Dyes Commonly Used to Assess Cytotoxicity. Carbon 2007, 45, 1425-1432.

(10) Monteiro-Riviere, N. A.; Inman, A. O.; Zhang, L. W. Limitations and Relative Utility of Screening Assays to Assess Engineered Nanoparticle Toxicity in a Human Cell Line. Toxicol. Appl. Pharmacol. 2009, 234, 222-235.

(11) Hirsch, C.; Kaiser, J.-P.; Wessling, F.; Fischer, K.; Roesslein, M.; Wick, P.; Krug, H. F. A Novel Comprehensive Evaluation Platform to Assess Nanoparticle Toxicity in Vitro. J. Phys. Conf. Ser. 2011, 304, 012053.

(12) Tournebize, J.; Sapin-Minet, A.; Bartosz, G.; Leroy, P.; Boudier, A. Pitfalls of Assays Devoted to Evaluation of Oxidative Stress Induced by Inorganic Nanoparticles. Talanta 2013, 116, 753-763.

(13) Oostingh, G. J.; Casals, E.; Italiani, P.; Colognato, R.; Stritzinger, R.; Ponti, J.; Pfaller, T.; Kohl, Y.; Ooms, D.; Favilli, F.; et al. Problems and Challenges in the Development and 
Validation of Human Cell-Based Assays to Determine Nanoparticle-Induced Immunomodulatory Effects. Part. Fibre Toxicol. 2011, 8, 8.

(14) Herseth, J. I.; Totlandsdal, A. I.; Bytingsvik, S.; Kaur, J.; Noer, M.; Bølling, A. K. The Challenge of Obtaining Correct Data for Cellular Release of Inflammatory Mediators after in Vitro Exposure to Particulate Matter. Toxicol. Lett. 2013, 221, 110-117.

(15) Stone, V.; Johnston, H.; Schins, R. P. F. Development of in Vitro Systems for Nanotoxicology: Methodological Considerations. Crit. Rev. Toxicol. 2009, 39, 613-626.

(16) Pailleux, M.; Boudard, D.; Pourchez, J.; Forest, V.; Grosseau, P.; Cottier, M. New Insight into Artifactual Phenomena during in Vitro Toxicity Assessment of Engineered Nanoparticles: Study of TNF-A Adsorption on Alumina Oxide Nanoparticle. Toxicol. Vitro Int. J. Publ. Assoc. BIBRA 2013, 27, 1049-1056.

(17) Holder, A. L.; Goth-Goldstein, R.; Lucas, D.; Koshland, C. P. Particle-Induced Artifacts in the MTT and LDH Viability Assays. Chem. Res. Toxicol. 2012, 25, 1885-1892.

(18) Breznan, D.; Das, D.; MacKinnon-Roy, C.; Simard, B.; Kumarathasan, P.; Vincent, R. Non-Specific Interaction of Carbon Nanotubes with the Resazurin Assay Reagent: Impact on in Vitro Assessment of Nanoparticle Cytotoxicity. Toxicol. Vitro Int. J. Publ. Assoc. BIBRA 2014.

(19) Figarol, A.; Pourchez, J.; Boudard, D.; Forest, V.; Tulliani, J.-M.; Lecompte, J.-P.; Cottier, M.; Bernache-Assollant, D.; Grosseau, P. Biological Response to Purification and Acid Functionalization of Carbon Nanotubes. J. Nanoparticle Res. 2014, 16, 1-12.

(20) Wang, G.; Zhang, J.; Dewilde, A. H.; Pal, A. K.; Bello, D.; Therrien, J. M.; Braunhut, S. J.; Marx, K. A. Understanding and Correcting for Carbon Nanotube Interferences with a Commercial LDH Cytotoxicity Assay. Toxicology 2012, 299, 99-111.

(21) Jones, C. F.; Grainger, D. W. In Vitro Assessments of Nanomaterial Toxicity. Adv. Drug Deliv. Rev. 2009, 61, 438-456. 
(22) Ali-Boucetta, H.; Al-Jamal, K. T.; Kostarelos, K. Cytotoxic Assessment of Carbon Nanotube Interaction with Cell Cultures. Methods Mol. Biol. Clifton NJ 2011, 726, 299312.

\section{Supporting information available.}

Five supplementary figures illustrate respectively: 1) the standard curve of absorbance at 450 $\mathrm{nm}$ of LDH solutions depending on the LDH concentration, 2) the absorbance of solutions containing $\mathrm{CNT}$ and $\mathrm{LDH}$ depending on the $\mathrm{CNT}$ concentration, 3) the adsorption isotherm of LDH on CNT for different concentrations of LDH reported by surface of $\mathrm{CNT}, 4)$ the linear regression for the determination of the parameters of the Langmuir model and 5) the adsorption isotherm of LDH on CNT with the Hasley, Temkin-Pyzhev and Freundlich models.

This material is available free of charge via the Internet at http://pubs.acs.org. 
Carbon $\quad$ can interfere with $\longrightarrow$ CNT intrinsic absorbance
nanotube $\Rightarrow$ LDH viability assay $\longrightarrow$ LDH adsorbed on CNT

Quantification of the artifacts in cell free condition
Modeling of the adsorption of LDH on CNT (Langmuir model)
Correction of the results from the assay in cellular conditions
Accurate results and reliable interpretation




\section{Supporting Information:}

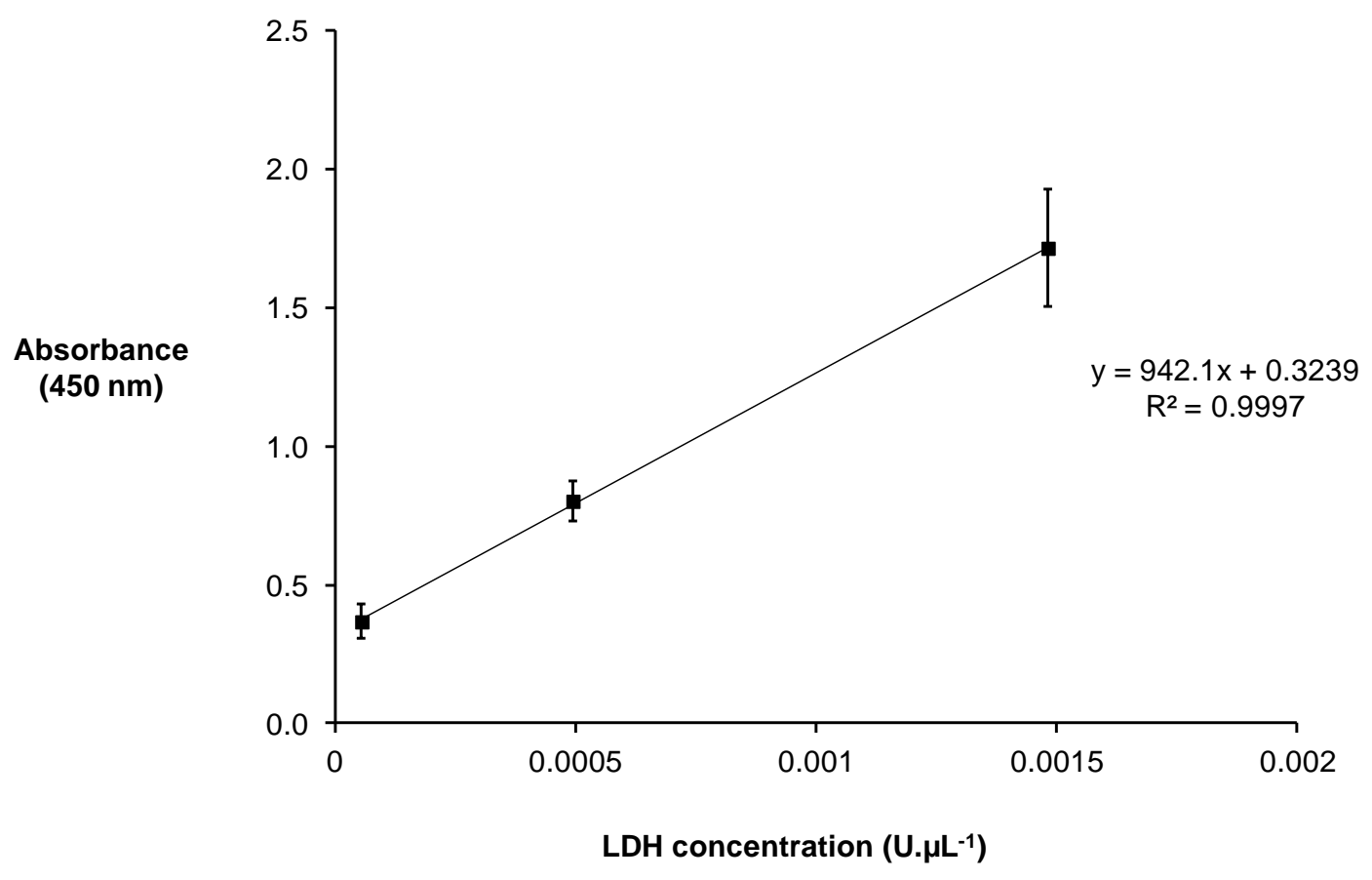

Supplementary Figure 1: Standard curve of absorbance at $450 \mathrm{~nm}$ of LDH solutions depending on the LDH concentration (without CNT). 


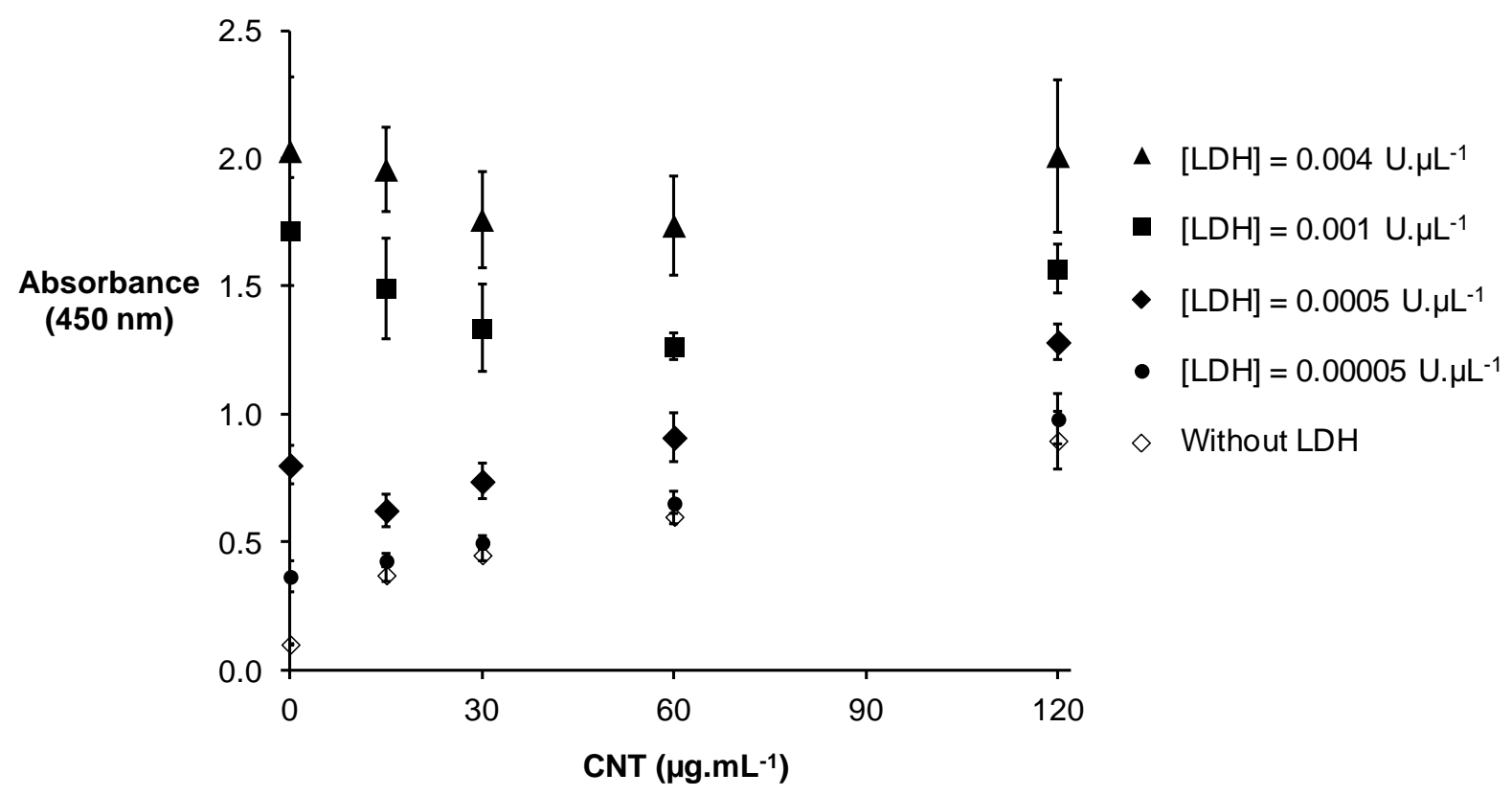

Supplementary Figure 2: Absorbance of solutions containing CNT and LDH depending on the CNT concentration. 


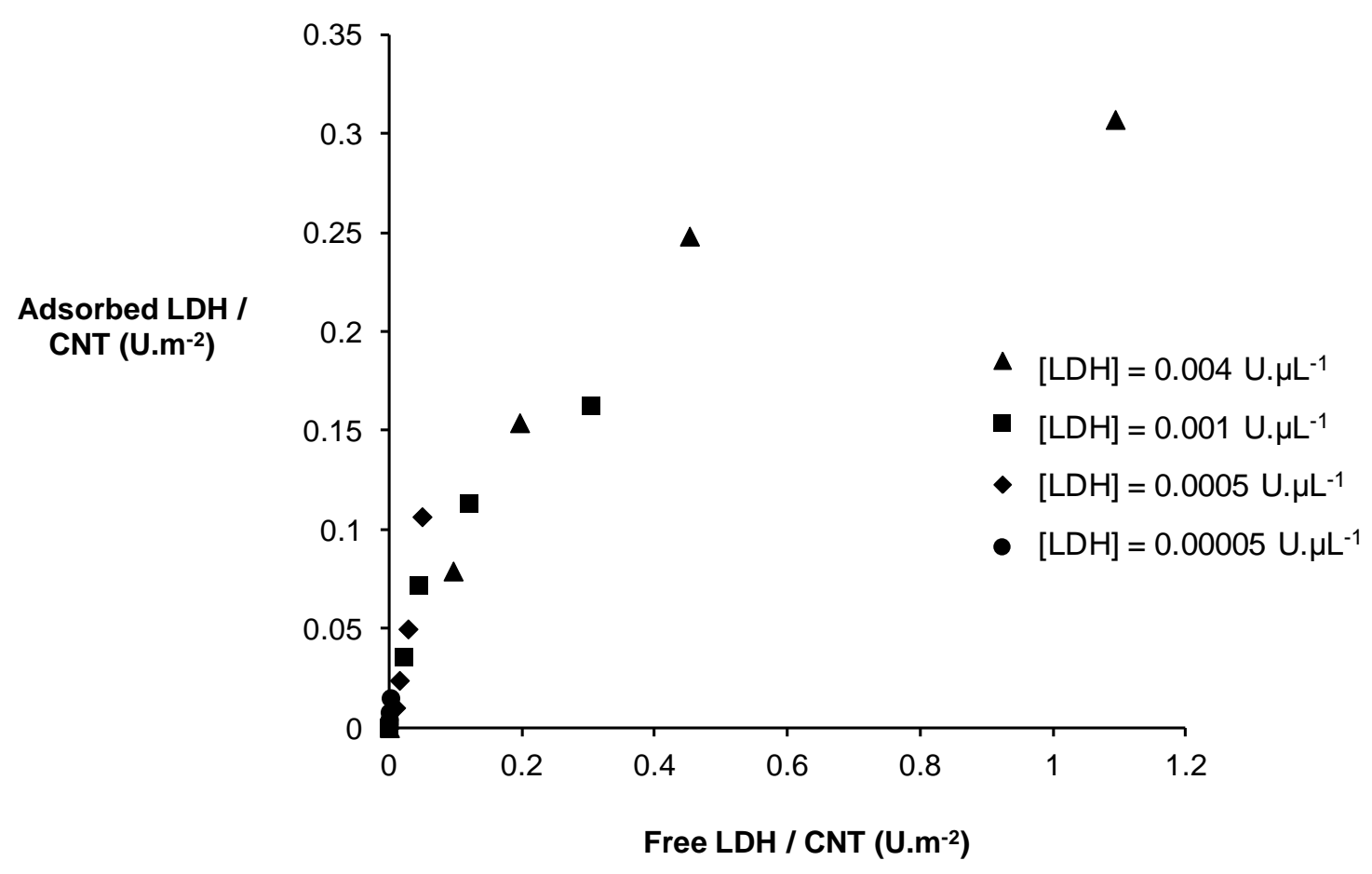

Supplementary Figure 3: Adsorption isotherm of LDH on CNT for different concentrations of LDH. Results are reported by surface (in $\left.\mathrm{m}^{2}\right)$ of CNT. 


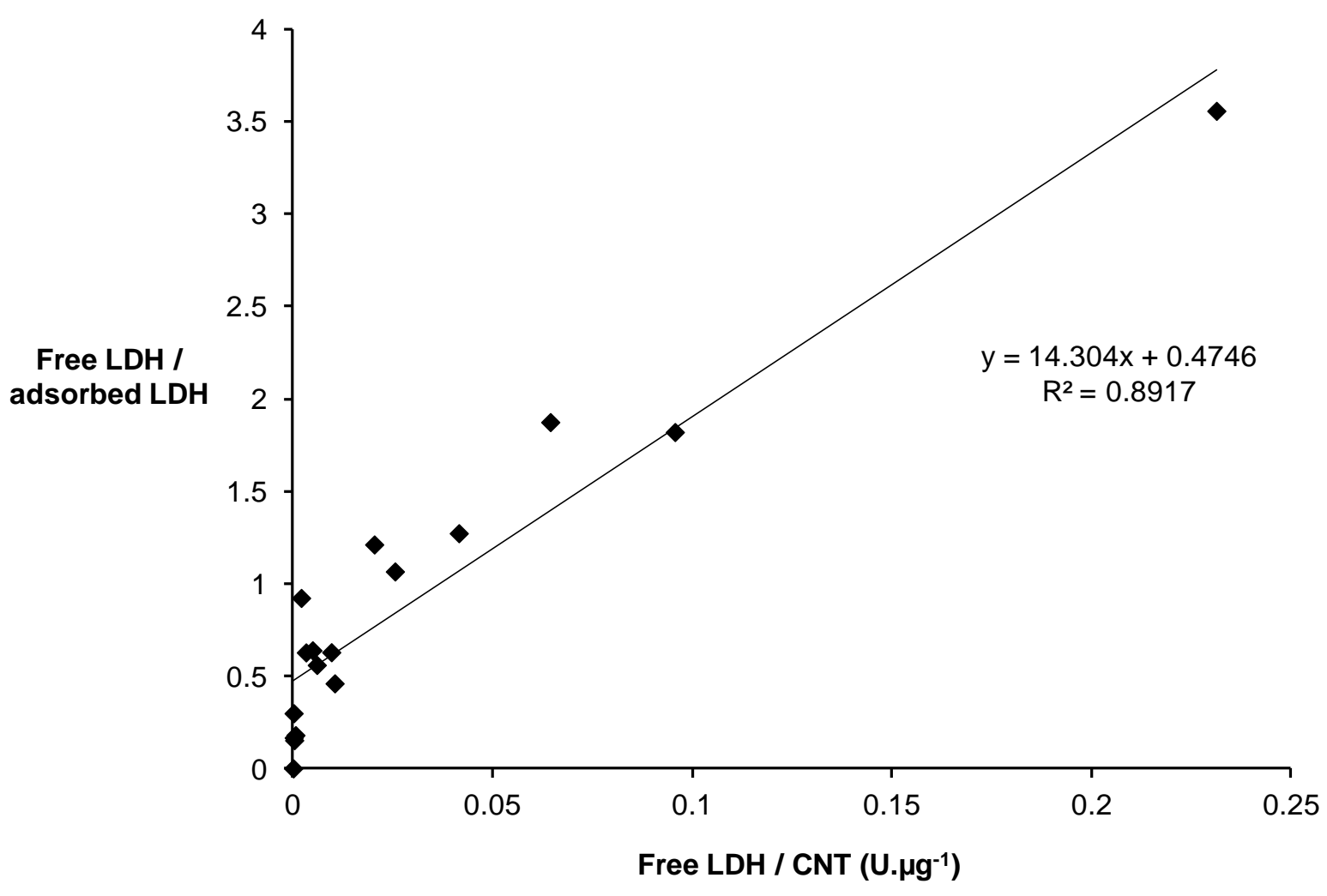

Supplementary Figure 4: Linear regression for the determination of the parameters of the Langmuir model. 


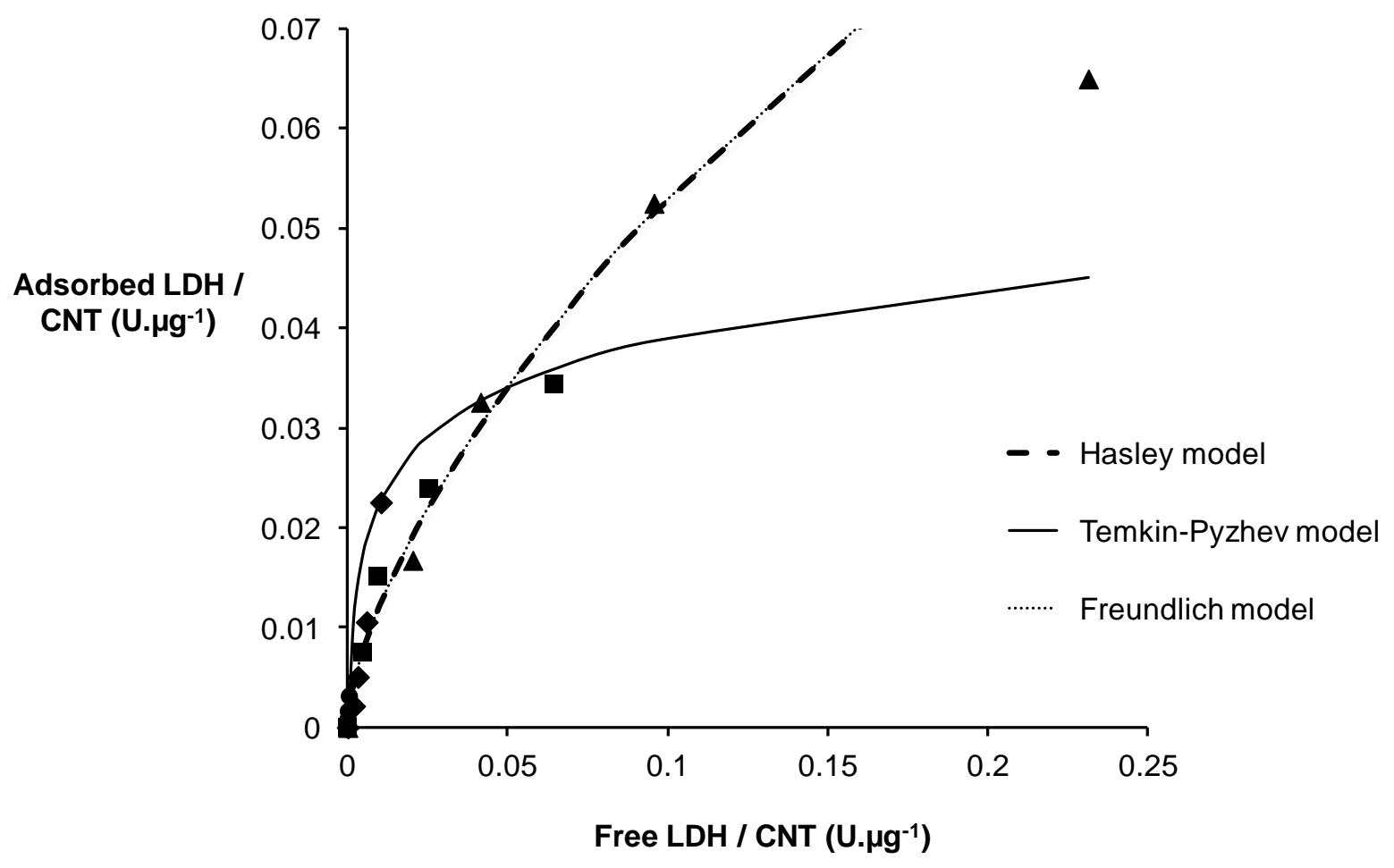

Supplementary Figure 5: Adsorption isotherm of LDH on CNT with the Hasley, TemkinPyzhev and Freundlich models. 